\title{
Systematic Review and Meta-Analysis of the Possible Concerns of 5G Radiation and Radiation Emitting Materials
}

\author{
Chris Canada and Muhammad Maqbool* \\ Department of Clinical \& Diagnostic Sciences, The University of Alabama at Birmingham, USA
}

Submitted: August 20, 2020; Published: October 05, 2020

*Corresponding author: Muhammad Maqbool, Department of Clinical \& Diagnostic Sciences, Health Physics Program, The University of Alabama at Birmingham, Birmingham, AL 35294, USA

\begin{abstract}
This mini review provides a brief introduction on the controversy surrounding the advent of $5 \mathrm{G}$ technology. Furthermore, it attempts provide general knowledge on antenna radiation to extend to laymen the possible effects of $5 \mathrm{G}$ cell towers by explaining the how a microwave radiation works and the mechanics of $5 \mathrm{G}$ radiation. Finally, it explores the honesty of the uncertainty surrounding the latest generation of wireless technology. It also discusses concerns about materials potentially capable to produce $5 \mathrm{G}$ radiation.
\end{abstract}

Keywords: 5G Radiation; 5G Emitting materials; Safety \& concerns

\section{Introduction}

Cell phone radiation has been a controversial topic for some time now with the new advent and planning for $5 \mathrm{G}$ cell towers [1-5]. The American Cancer Society states that since radiation is relatively low compared to gamma rays and ultraviolet light, it is not strong enough to break chemical bonds in DNA and thus is not a threat of cancer [3-6]. They also contend that the waves are too long to be concentrated within the body thus there would likely be no effect on the cellular level since cells are many times smaller than the wave [7-11]. Lastly, they contend that the towers are at a safe distance, so even if you were exposed to such radiation, it would be like being exposed to background radiation [9-14]. It is well understood that this new $5 \mathrm{G}$ technology promises faster connections and download speeds however, it can also give great enhancements with developing technologies such as autonomous cars, smart cities, and virtual reality. From an economic perspective it would make sense to further investigate $5 \mathrm{G}$ to strengthen the potential of these hot commodities and lucrative avenues. The caveat is, there is a knowledge gap regarding the health effects of $5 \mathrm{G}$ radiation. The predecessors of $5 \mathrm{G}$, such as $3 \mathrm{G}$ and $4 \mathrm{G}$ have been extensively studied. These studies seem to suggest that cell phone radiation can lead to adverse effects [10-16]. Thus, the public concern is that increasing the frequency of the radiation will also increase the effects of the radiation [14-16].
This review does not try to dispute the idea that radiation related to cell phones and cell towers will not have adverse effects. However, the purpose of this paper is to explain the basics of radiation within the radiofrequency spectrum and to exploit possible concerns and byproducts that should be taking into consideration if $5 \mathrm{G}$ radiation is to be implemented into the cell phone industry.

\section{Working Mechanism}

To understand possible effects of $5 \mathrm{G}$ radiation, it is important to know the basics of radio frequencies to thereby apply the mechanics in different situations. Looking at microwave ovens is a good place to derive how radio frequencies are created. The general idea of the workings of the microwave is that the electromagnetic waves administered at radio frequencies are constantly oscillating. When these oscillating electromagnetic waves interact with dipolar molecules such as water (which are molecules that are positively charged at one end and negatively charged at the other end) the oscillating field of the electromagnetic wave causes the molecule to rotate in an increasing manner [1618]. This oscillating rotation causes proximal molecules to bump against each other thereby causing friction while also increases the kinetic energy within the system, which ultimately increases 
the thermal energy of the target substance in the microwave. While the surface of the target substance heats up the slightly quicker due to the fact it is the outer layer that is first exposed to incident radiation, the electromagnetic waves are penetrating at the given radio frequencies, thus given enough time one can expect a near uniform distribution of thermal energy inside the subject, though it is not uncommon to see various cold and hot spots in the target substance due to various peaks and nodes of the electromagnetic wave effecting the target. The focal point of microwave production lies within the magnetron. The magnetron contains cooling fins which are thinly sliced plates used to dissipate the acquired heat. The other component of the magnetron are two magnets and a vacuum tube.

To harness the electromagnetic wave at a specific frequency you must send a voltage through the filament in the center. The filament is made out tungsten being it has a high thermal tolerance and thorium because it is rich with electrons. The filament heats up which causes electrons to escape where they proceed to head towards the outer copper anode. The magnetic field causes the path of the electron to bend back from which it came. The strength of the magnetic must maintain the optimum field so the electrons proceed with their optimal orbits which thus allows for radio frequencies to seep through the cavities.

\section{G Mechanics}

When discussing the mechanics of $5 \mathrm{G}$ it is important to understand the innovations through each generation. The first generation was the first cell phone. $2 \mathrm{G}$ gave us the opportunity to send text messages. $3 \mathrm{G}$ gave us the freedom to use the internet.
$4 \mathrm{G}$ increased the overall speed of the previous applications. And $5 \mathrm{G}$ as cited earlier comes with better connections and download speeds. These features are accomplished with 5 components of 5G which include millimeter waves, small cells, massive MIMO, beamforming, and full duplex. The first component of millimeter waves is indictive of the specific part of the electromagnetic spectrum used. Radio frequencies is the part of the spectrum that ranges from $3 \mathrm{kHz}$ to $300 \mathrm{GHz}$. Typically, $4 \mathrm{G}$ operates from 2-6 GHz. The issue is that as more cell phones come online, there will be less space available and more crowded lines [15-19]. This problem has pushed scientists to study possible ways of increasing the spectrum to reach beyond the standard $4 \mathrm{G}$ level of 6 $\mathrm{GHz}$. This leads us to the second component of small cell networks because the higher frequencies tend to get absorbed easily by things like trees and buildings which are common in cities and rural areas. These small cell towers will be a lot smaller and use a lot less power than the predecessor $4 \mathrm{G}$ tower which was larger and operating at a much higher wattage. The third component is massive MIMO which means multiple input multiple output and is understood as the device to hold on the ongoing and incoming traffic signals.

All those signals will have overlaps once redistributed; thus the fourth component is needed, the beam former, which filter the signals to the specified device. The beam former uses timing and algorithms to accomplish effective redistribution of incoming and outgoing cell signals [17-20]. The full duplex is the part of the system that allows for multiple people to talk at the same time because of the route it gives the given incoming signals.

\section{Possible Effects}

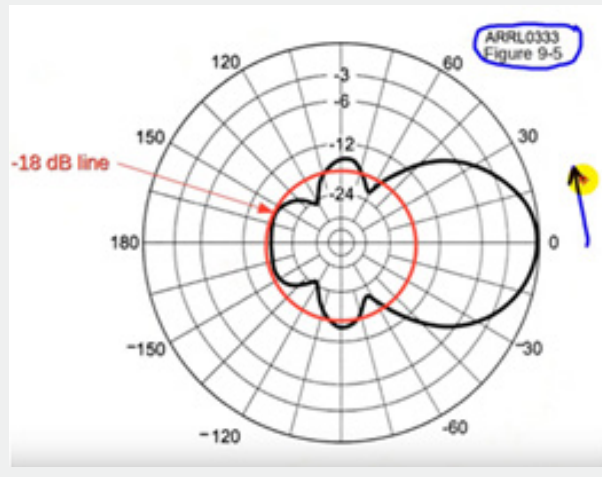

Figure 1: The Radiation Pattern shows that distance does not necessarily indicate the amount of Radiation you will be exposed to.

Antennas are the focal point of wireless communications. Cell phone companies have managed to engineer ways of constructing the antenna to release desirable wave formations. Thus, different antennas will create electromagnetic waves of different forms. Thereby when calculating the potential risk of cell tower radiation, it is important to note that if a group of people were standing in a circle equidistant from the source antenna, they might not necessarily revive the same amount of radiation depending on the shape of the wave [14-16, 18-21] (Figures 1-3). 5G towers are going to emit electromagnetic waves at a higher frequency. Higher frequency waves do not travel as far, and they are less penetrating. Thus, there will be many $5 \mathrm{G}$ cell towers implemented in close proximity with one another so you can have a constant strong connection. The caveat to this that since the cell towers will be in close proximity with one another there is a chance for the electromagnetic waves to overlap with one another. This overlap 
could cause destructive interference where at certain spots there will not be a strong connection due to the emergent collapse of the signal [22-26]. Another effect could be that the electromagnetic waves will overlap and cause constructive interference. This could cause people to be exposed to excess radiation and thus pose as health risk to people working near such an environment. Thereby electromagnetic wave overlap should be taken into consideration before the advent of releasing $5 \mathrm{G}$ cell towers in close proximity to one another (Figure 4). Photons tend to scatter. Thus, there might be a convulsion effect where certain spots are exceeding the expected radiation concentration. This could result in a hot spot or signaling issues due to the unexpected decibel gains.

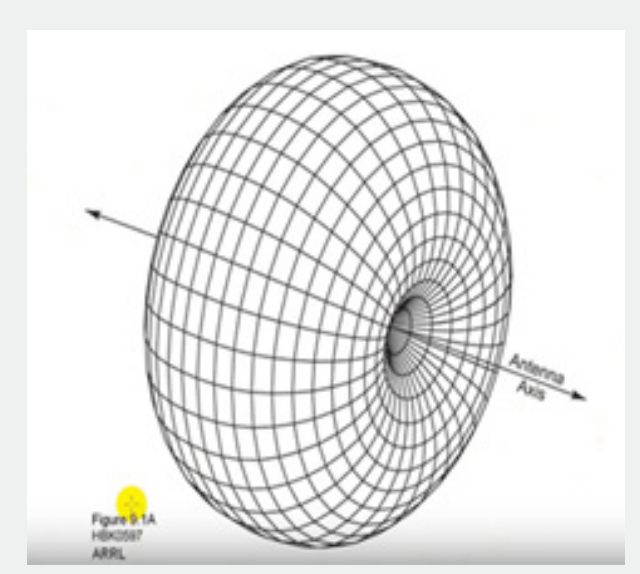

Figure 2: The Typical Emission Pattern of Antennas before any manipulation for Optimum Beam Direction.

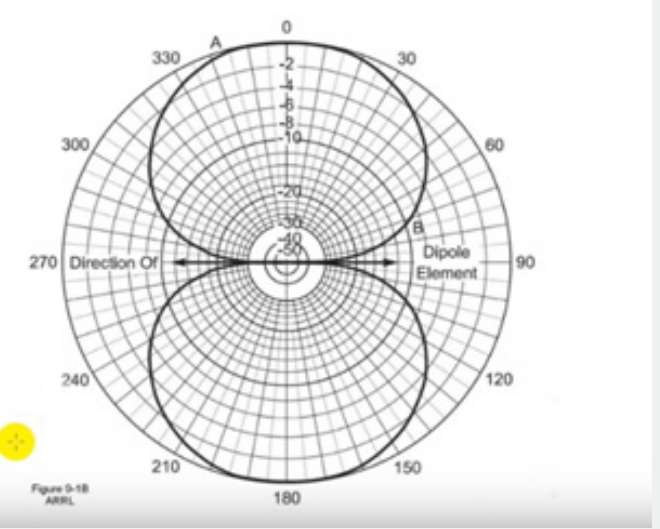

Figure 3: A Cross-Sectional view of the Torus Shaped Radiation Pattern.

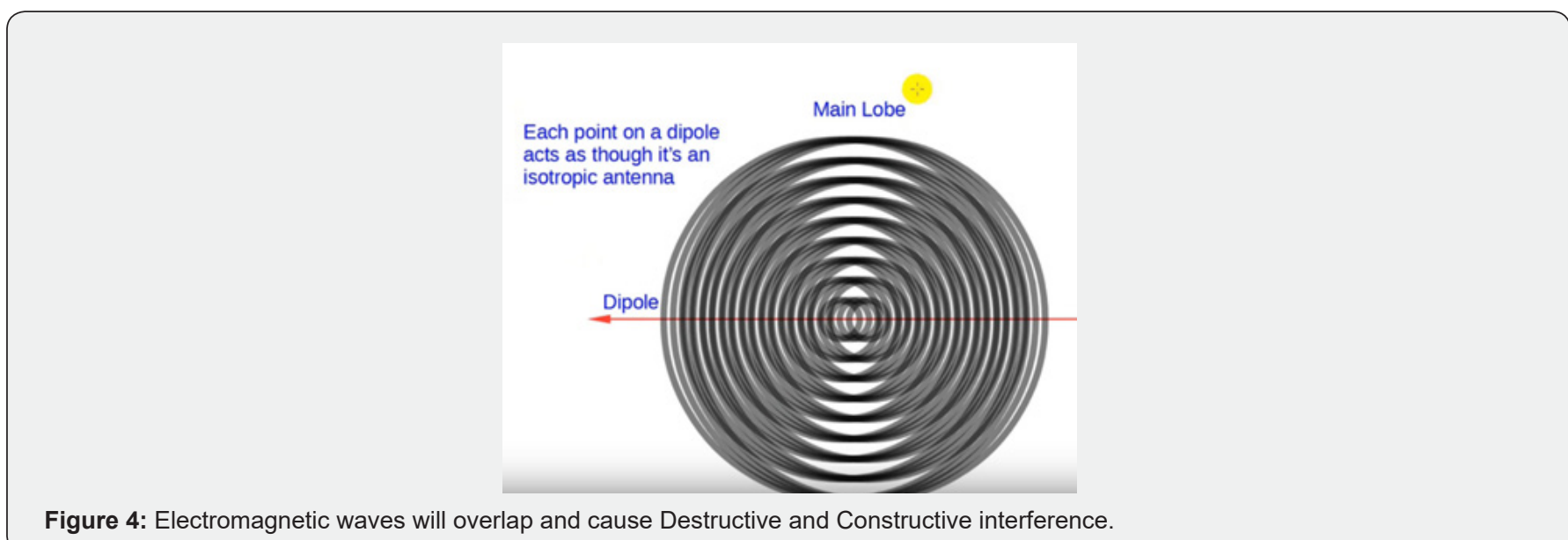


Another possible effect is that being so close to cell towers can cause one to receive constant doses of radiation. This has been shown to have adverse effects for example people who live near cell towers had reported to have higher rates of headaches as compared to people who do not live close to cell towers. Studies also show that long term exposure at frequencies within $900-1800 \mathrm{MHz}$ influenced DNA integrity and even induced hippocampal damage. Moreover, studies displayed that in human neuroblastoma cells there was a higher chance of susceptibility to oxidative stress even after only being exposed to electromagnetic waves at $1800 \mathrm{MHz}$ for approximately 10 minutes [24-27]. If these potential effects are ignored there should be at least a stronger push in safety warning regarding the amount of radiation you receive from your cell phone. iPhone have made a push to where you can go into your settings and read a warning about the specific absorption rate limits and how to limit your exposure by simply using the hands-free mode or talking on the phone with speaker mode. However, the common user will not think twice to review these statements [26-29].

\section{Conclusion}

i. In conclusion, rather or not the public concern of 5G radiation is legitimate can be argued either way. However, if we agree that health is the primary factor in determining the viability of new technology, then the fact remains that there are many considerations that need to be addressed before the implementation of $5 \mathrm{G}$ cell towers. The uncertainty of the putting up the towers could be detrimental being there are so many towers they would affect populations on a large scale. Moreover, it would make more sense from a economical standpoint to $5 \mathrm{G}$ cell towers in close proximity to one another. out the effects of $5 \mathrm{G}$ towers before we spend money putting them up.

\section{References}

1. Mugunthan N, Shanmugasamy K, Anbalagan J, Swamynathan Rajanarayanan, Swamynathan Meenachi (2016) Effects of long term exposure of 900-1800 $\mathrm{MHz}$ radiation emitted from $2 \mathrm{G}$ mobile phone on mice hippocampus-a histomorphometric study. J Clin Diagn Res 10(8): AF01-AF06.

2. Marjanovic CAM, Pavicic I, Trosic I (2018) Oxidative stress response in SH-SY5Y cells exposed to short-term $1800 \mathrm{MHz}$ radiofrequency radiation. J Environ Sci Health A Tox Hazard Subst Environ Eng 53(2): 132-138.

3. Rushabh D, Rinki H (2015) Effect of Mobile Phone Radiations on Oral Health. J Int Oral Health 7(1): 1-2.

4. Lönn S, Ahlbom A, Hall P, Feychting M (2004) Mobile phone use and the risk of acoustic neuroma. Epidemiology 15(6): 653-659.

5. Hardell L, Carlberg M, Söderqvist F, Mild KH, Morgan LL (2007) Long-term use of cellular phones and brain tumours: Increased risk associated with use for $>$ or $=10$ years. Occup Environ Med 64(9): 626632.

6. Myung SK, Ju W, McDonnell DD, Lee YJ, Kazinets G, et al. (2009) Mobile phone use and risk of tumors: A meta-analysis. J Clin Oncol 27(33): 5565-5572.

7. Repacholi MH, Lerchl A, Röösli M, Sienkiewicz Z, Auvinen A, et al.
(2012) Systematic review of wireless phone use and brain cancer and other head tumors. Bioelectromagnetics 33(3):187-206.

8. Dasdag S, Yavuz I, Bakkal M, Kargul B (2014) Effect of long term 900 $\mathrm{MHz}$ radiofrequency radiation on enamel microhardness of rat's teeth. Oral Health Dent Manag 13(3):749-752.

9. Hintzsche H, Stopper H (2010) Micronucleus frequency in buccal mucosa cells of mobile phone users. Toxicol Lett 193(1): 124-130.

10. Bhargava S, Motwani MB, Patni VM (2012) Effect of handheld mobile phone use on parotid gland salivary flow rate and volume. Oral Surg Oral Med Oral Pathol Oral Radiol 114(2): 200-206.

11. Keykhosravi A, Neamatshahi M, Mahmoodi R, Navipour E (2018) Radiation Effects of Mobile Phones and Tablets on the Skin: A Systematic Review. Advances in Medicine 2018, p. 1-5.

12. Carlberg M, Hedendahl L, Koppel T, Hardell L (2019) High ambient radiofrequency radiation in Stockholm city, Sweden. Oncol Lett 17(2): 1777-1783.

13. Hardell L, Carlberg M, Hedendahl LK (2018) Radiofrequency radiation from nearby base stations gives high levels in an apartment in Stockholm, Sweden: A case report. Oncol Lett 15(5): 7871-7883.

14. Halgamuge MN (2017) Review: weak radiofrequency radiation exposure from mobile phone radiation on plants. Electromagn Biol Med 36(2): 213-235.

15. Waldmann-Selsam C, Balmori-de la Plante A, Breunig H, Balmori A (2016) Radiofrequency radiation injures trees around mobile phone base stations. Sci Total Environ 572: 554-569.

16. ICNIRP (1998) Guidelines for limiting exposure to time-varying electric, magnetic, and electromagnetic fields (up to $300 \mathrm{GHz}$ ). International commission on non-ionizing radiation protection. Health Phys 74: 494-522.

17. Philips A, Henshaw DL, Lamburn G, O Carroll MJ (2018) Brain tumours: rise in glioblastoma multiforme incidence in England 1995-2015 suggests an adverse environmental or lifestyle factor. J Public Health Environ pp. 1-10.

18. Röösli M, Lagorio S, Schoemaker MJ, Schüz J, Feychting M (2019) Brain and salivary gland tumors and mobile phone use: evaluating the evidence from various epidemiological study designs. Annu Rev Public Health 40: 221-238.

19. Söderqvist F, Carlberg M, Hardell L (2012) Review of four publications on the Danish cohort study on mobile phone subscribers and risk of brain tumours. Rev Environ Health 27(1): 51-58.

20. Goedhart G, Van Wel L, Langer CE, De Llobet Viladoms P, Wiart J, et al. (2018) Recall of mobile phone usage and laterality in young people: the multinational Mobi-Expo study. Environ Res 165: 150-157.

21. Lerchl A, Klose M, Grote K, Wilhelm AF, Spathmann O, et al. (2015) Tumor promotion by exposure to radiofrequency electromagnetic fields below exposure limits for humans. Biochem Biophys Res Commun 459(4): 585-590.

22. Vijayalaxmi, Prihoda TJ (2019) Comprehensive review of quality of publications and meta-analysis of genetic damage in mammalian cells exposed to non-ionizing radiofrequency fields. Radiat Res 191(1): 2030.

23. Fernández C, De Salles AA, Sears ME, Morris RD, Davis DL (2018) Absorption of wireless radiation in the child versus adult brain and eye from cell phone conversation or virtual reality. Environ Res 167: 694-699.

24. Choi KH, Ha M, Ha EH, Park H, Kim Y, et al. (2017) Neurodevelopment for the first three years following prenatal mobile phone use, radio frequency radiation and lead exposure. Environ Res 156: 810-817. 
25. Byun YH, Ha M, Kwon HJ, Hong YC, Leem JH, et al. (2013) Mobile phone use, blood lead levels, and attention deficit hyperactivity symptoms in children: a longitudinal study. PLoS ONE 8(3): e59742.

26. Elwood JM (2003) Epidemiological studies of radio frequency exposures and human cancer. Bioelectromagnetics 24(S6):63-73.

27. Sharma VP, Singh HP, Kohli RK, Batish DR (2009) Mobile phone radiation inhibits Vignaradiata (mung bean) root growth by inducing oxidative stress. Sci Total Environ 407(21): 5543-5547.
28. Challis LJ (2005) Mechanisms for interaction between RF fields and biological tissue. Bioelectromagnetics 7: S98-S106.

29. Răcuciu MI, Miclăuş SI (2007) Low-level 900 MHz electromagnetic field influence on vegetal tissue. Rom J Biophys 17(3):149-156.

This work is licensed under Creative Commons Attribution 4.0 License

DOI: 10.19080/JOJMS.2020.06.555689 